\title{
Developing Mg-Zn-Fish Bone Derived Hydroxyapatite Composites for Biomedical Applications: In vitro Degradation Studies
}

\author{
Manoj Kumar Elipey 1(D), Talakayala Sunil Kumar ${ }^{2}$ (D), Ravikumar Dumpala ${ }^{3(D)}$, Ratna Sunil \\ Bradagunta 4 ,*(i)
}

1 Department of Mechanical Engineering, Vardhaman College of Engineering, Shamshabad 501218, India; emanoj2000@gmail.com (M.K.E);

2 Department of Mechanical Engineering, Geethanjali Institute of Science \& Technology, Gangavaram 524137, India; suneilkumart@gmail.com (T.S.K.);

3 Department of Mechanical Engineering, Visvesvaraya National Institute of Technology, Nagpur 440010, India; ravikumardumpala@mec.vnit.ac.in (R.K.D.);

4 Department of Mechanical Engineering, Bapatla Engineering College, Bapatla 522101, India; bratnasunil@gmail.com (B.R.S.);

* Correspondence: bratnasunil@gmail.com (B.R.S.);

Scopus Author ID 35410353400

Received: 16.09.2021; Revised: 15.10.2021; Accepted: 18.10.2021; Published: 21.11.2021

\begin{abstract}
The study of magnesium $(\mathrm{Mg})$ based biomaterials has emerged as a potential research area in recent times. Controlling the rapid corrosion and improving the implant-tissue interface kinetics for better tissue regeneration are the prime interests behind developing novel $\mathrm{Mg}$-based composites. In the current work, the metal matrix composites of $\mathrm{Mg}-\mathrm{Zn}$, dispersed with nano-hydroxyapatite derived from fish bones (fHA), were produced by powder metallurgy route. The powders were mixed with the help of ball milling in the presence of ethanol and then sintered at $440{ }^{\circ} \mathrm{C}$. From the microstructural studies, micro-lamellar morphology was noticed for the sintered compacts due to the flake-like morphology of the milled powders. The sintered compacts were then subjected to in vitro biodegradation studies in simulated conditions for one week. From the results, the presence of fHA was found to be highly influential in increasing the rate of mineral deposition on the surface of the composites. These higher mineral depositions protected the surface of the composites from further degradation. The results demonstrate that adding fHA to $\mathrm{Mg}$ accelerates biomineralization and controls degradation, leading to better implant-tissue interactions.
\end{abstract}

Keywords: fish bones; calcium phases; degradable implants; surface degradation; biomineralization.

(C) 2021 by the authors. This article is an open-access article distributed under the terms and conditions of the Creative Commons Attribution (CC BY) license (https://creativecommons.org/licenses/by/4.0/).

\section{Introduction}

Developing composite materials by combining different phases helps material scientists to produce modern materials with hybrid properties [1]. Metals exhibit superior mechanical properties required to manufacture load-bearing medical implants compared with polymers and ceramic materials. On the other hand, ceramic materials possess excellent biocompatibility. Calcium-based ceramics exhibit bioactive nature and can develop strong bonding with the tissue [2]. Hence, developing composites by incorporating bioactive ceramic phases helps to produce novel biomaterials with desired properties [3,4]. For the past two decades, significant interest has been shown in developing magnesium $(\mathrm{Mg})$ based implants for orthopedic applications due to excellent bio-properties [5-8]. The main objective of the research groups 
across the globe on developing $\mathrm{Mg}$ implants is to control the rapid degradation and to enhance the tissue bonding at the implant interface [9-12]. In this context, incorporating bioactive ceramic phases into $\mathrm{Mg}$-based materials to develop composites is a promising strategy [13-16].

Hydroxyapatite (HA) is a ceramic phase of calcium $(\mathrm{Ca})$ and phosphorous $(\mathrm{P})$ that can be seen in higher fractions in the bones of mammals. Human bones also contain HA crystals at the nano-level and collagen and other growth factors [17]. HA is used as bone filling material, medium for targeted drug delivery, and to manufacture dental implants in biomedical applications $[18,19]$. HA can be obtained by natural resources or can be synthesized in the laboratory. For naturally derived HA, fish bones, scalps, sea corals, eggshells, etc., can be used as precursors [20-24]. Synthetically produced HA is obtained by using specific chemicals such as calcium hydroxide, calcium nitrates, ammonium phosphates, etc., in appropriate proportions by following various protocols as reported in the literature [25-28]. HA derived from natural resources contains additional ions. In our earlier work, nano-HA was successfully synthesized from fish bones (rohio), and the presence of zinc was noticed in addition to calcium and phosphorous [29].

Ball milling is a powder processing technique in which powders are uniformly mixed and repeatedly subjected to the collision between the balls. Prolonged milling times also help to reduce the particle size [30]. Developing composites by powder metallurgy needs appropriate blending of the powders of the constituting phases. The powder blends are then compacted by applying pressure and heat in a protected environment or vacuum with a proper heating rate. This process in powder metallurgy is known as sintering. Since the process is carried out in solid-state, the issues associated with the liquid state, such as oxidation, formation of new phases, and decomposition of existing phases, can be eliminated. Other processes such as powder mixing and hot extrusion, melting and extrusion, friction stir processing, spark plasma sintering can be seen in the literature in developing composites of $\mathrm{Mg}$ for medical implant applications [31-35]. Being an essential micronutrient, zinc $(\mathrm{Zn})$ is required for several metabolic activities in the human body. $\mathrm{Mg}$ - $\mathrm{Zn}$ alloys were demonstrated as one of the promising $\mathrm{Mg}$ alloy systems for biomedical applications [12]. Information on using ioncontaining HA, such as naturally derived HA, as a reinforcing material to develop Mg-based implants is insufficient in the reported scientific literature. Hence in the present work, fish bone-derived nano-HA (fHA) was dispersed into pure $\mathrm{Mg}$ using ball milling, and the milled powders were consolidated by sintering at $440{ }^{\circ} \mathrm{C}$. The effect of adding fHA on biomineralization was assessed by conducting in vitro bioactivity studies in simulated conditions.

\section{Materials and Methods}

Pure Mg powder (99.5\% purity, Merk, India) and pure Zn powder (99.9 \% purity, Quality Traders, Guntur, India) were procured and used in the present work. Fish bone-derived hydroxyapatite (fHA) was produced in the laboratory from fish (Rohio) bones. The procedure to synthesize nano-HA from fish bones can be referred to in our earlier report [29]. In the present composition, the $\mathrm{Zn}$ fraction was limited to $1 \%$, as the solubility limit of $\mathrm{Zn}$ element (solute) into $\mathrm{Mg}$ lattice (solvent) is less than $1 \%$ at the room temperature [28, 36]. Excess amount of $\mathrm{Zn}$ leads to develop MgZn intermetallics, which increase the degradation rate due to bio-corrosion [37,38]. Different percentages of fHA (1 and 2 wt.\%) were added to $\mathrm{Mg}$ $1 \% \mathrm{Zn}$, and composites were developed. A higher fraction of reinforcements in the $\mathrm{Mg}$ matrix accelerates the degradation rate in the corroding environment. Hence, the addition of fHA was 
limited to lower amounts ( 1 and $2 \%$ ). The powders with appropriate weights were milled by using a planetary ball mill for $20 \mathrm{~h}$. Tungsten carbide (WC) vials and balls were used for the milling process. Total balls weight to milling powder weight ratio was maintained as 20:1. Ethyl alcohol was filled in the vial before milling about covering the powders completely. After ball milling, the collected powders were dried and compacted in a cylindrical die of $10 \mathrm{~mm}$ diameter using a hydraulic press. X-ray diffraction (XRD) studies (using $\mathrm{CuK} \alpha$ ) have been carried out between 20 to $80^{\circ}$ for all the powder samples with a scanning step size of 0.1 . The compacted pellets were then placed in a furnace, and sintering was done at $440{ }^{\circ} \mathrm{C}$ in the presence of Argon gas. Heating of $5{ }^{\circ} \mathrm{C} / \mathrm{min}$ was adopted, and $1 \mathrm{~h}$ of soaking time was given to stabilize the temperature throughout the samples. Then the samples were furnace cooled and named as $\mathrm{Mg}-\mathrm{Zn}, \mathrm{Mg}-\mathrm{Zn}-1 \mathrm{fHA}$, and $\mathrm{Mg}-\mathrm{Zn}-2 \mathrm{fHA}$ for 0 , 1, and 2 percent of added fHA, respectively. Figure 1 shows the sintering cycle and typical photograph of $\mathrm{Mg}-\mathrm{Zn}-2 \mathrm{fHA}$ composite.

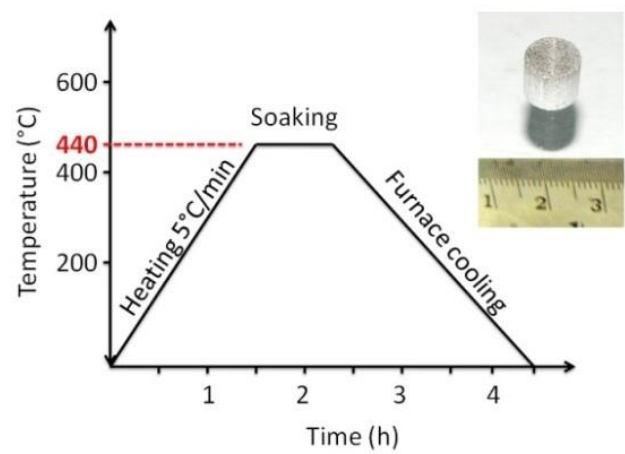

Figure 1. The heating, soaking, and cooling cycle adopted in the current work (inset: typical photograph of sintered Mg-Zn-2fHA composite).

A standard metallurgical procedure was adopted to prepare the samples for polishing [35]. After etching with a picric acid agent, microstructures were recorded using an optical microscope (Leica, Germany). Simulated physiological test conditions were provided by preparing a solution with a similar ion concentration of human blood plasma in the laboratory. The protocol for preparing the simulated body fluid (SBF) and the lab grade chemicals and their relative weights can be referred elsewhere [39]. The samples of size $10 \mathrm{~mm}$ diameter and $5 \mathrm{~mm}$ height were prepared, polished, and cleaned for immersion studies. While preparing the $\mathrm{SBF}$, the appropriate amount of ammonia was added to maintain a $\mathrm{pH}$ of $\sim 7.4$. Each container was filled with $50 \mathrm{ml}$ of SBF, and then the samples were placed in the containers. The weights of the samples were recorded before and after the immersion test to calculate the weight loss after one day and one week. Usually, for $\mathrm{Mg}$ alloys, rapid degradation is observed during the initial hours of degradation. Understanding the degradation behavior of $\mathrm{Mg}$-based material during initial hours is crucial in developing Mg-based implants. Hence, immersion studies have been conducted for one week. The $\mathrm{pH}$ of the solution was recorded every $12 \mathrm{~h}$ for all the samples. After one day and one week, all the samples were collected and placed in a container of distilled water (for $30 \mathrm{~min}$ ) and then dried in an open atmosphere. The morphologies of the powders and the immersed samples were analyzed by scanning electron microscope (SEM, TESCON, Czech Republic), and energy-dispersive X-ray spectroscopy (EDS) was also carried out. The samples after the immersion test were placed in chromate aqua solution ( $180 \mathrm{~g}$ of $\mathrm{CrO}_{3}$ has been added to $100 \mathrm{ml}$ of boiling water) to dissolve the corrosion products produced during the degradation process. After $30 \mathrm{~min}$, the corrosion products from the surface of the immersion samples were observed as completely dissolved in the chromate aqua solution. Then the weight 
of the degraded samples was measured to assess the weight loss $\left(\mathrm{mg} / \mathrm{cm}^{2}\right)$. The difference between the weight of the samples before immersion and after dissolving the corrosion products was obtained and divided by the surface area of the samples.

\section{Results and Discussion}

The Mg powders used to produce the composites, as shown in Figure 2(a), have an average size of $172 \pm 4.1 \mu \mathrm{m}$. The corresponding EDS analysis (Figure 2 (b)) confirms that the particles are free from impurities. Bright-field TEM image (Figure 2 (c)) of nanohydroxyapatite produced from fish bones (fHA) shows equiaxed morphology with an average size of $\sim 75 \mathrm{~nm}$. The selective area electron diffraction (SAED) pattern of produced fHA shows spots arranged in ring pattern (Figure 2(d)) which confirms the nano-dimension of the produced fHA. Ball milling for lower periods helps to mix the powders appropriately. If milling time is increased to higher periods, cold welding and fracturing of particles, size reduction, and uniform distribution of reinforcing phases into the matrix particles can be achieved [40].
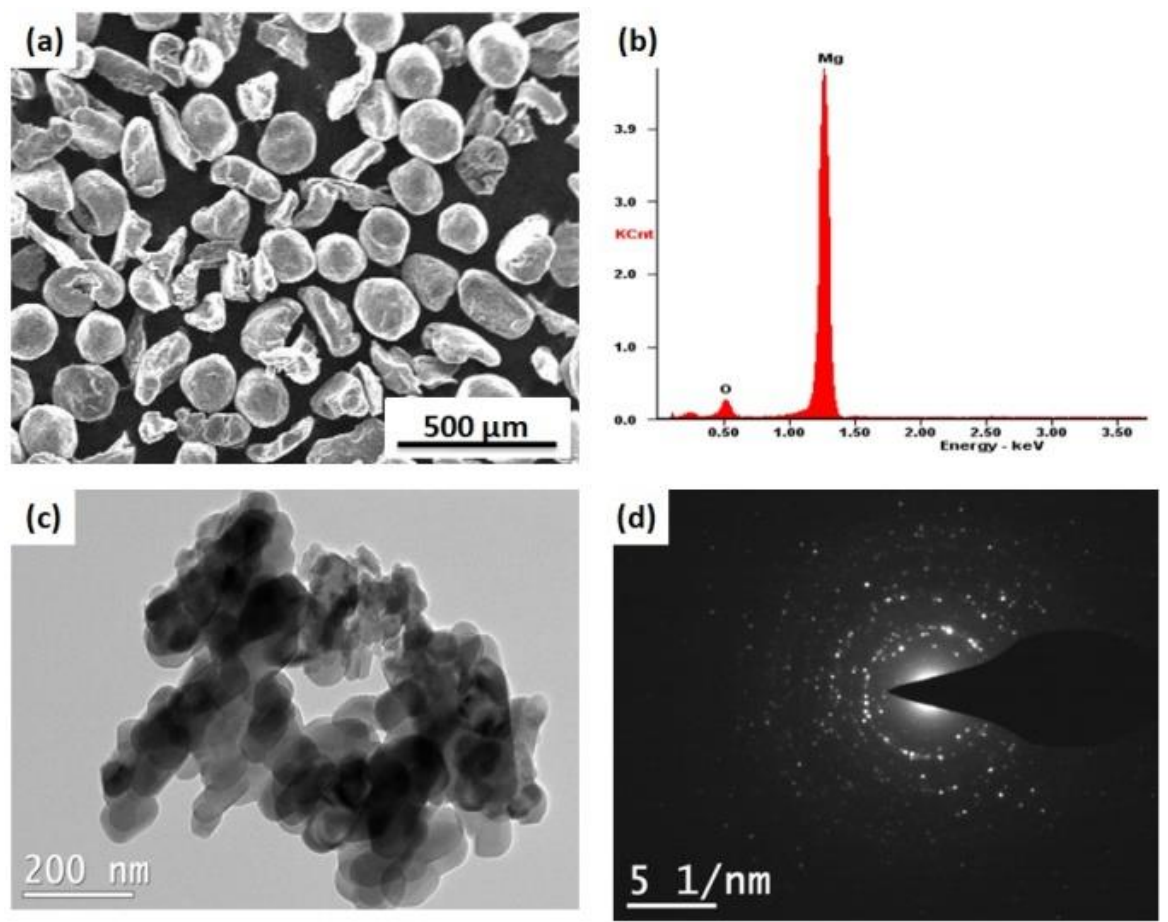

Figure 2. (a) SEM images of pure Mg powders and (b) EDS analysis, (c) bright-field transmission electron microscope image of fHA, and (d) corresponding SAED pattern.

Figure 3 shows the morphologies of ball-milled powders after $20 \mathrm{~h}$ of milling. Usually, particle size is greatly reduced after such long milling periods, as reported in the literature [40]. From the results, it can be learned that pure $\mathrm{Mg}, \mathrm{Mg}-\mathrm{Zn}-1 \mathrm{fHA}$, and $\mathrm{Mg}-\mathrm{Zn}-2 \mathrm{fHA}$ powders have transformed into flake-like morphology. Since $\mathrm{Mg}$ is soft, the particles were subjected to plastic deformation and deformed as thin flakes due to milling, and the thickness was significantly decreased. The size distribution of $\mathrm{Mg}$ particles after milling was found to be in a wide range between sub-micrometers to around $50 \mu \mathrm{m}$. The corresponding EDS analysis of the composites (Fig 3 (d) and (f)) shows the presence of calcium and phosphorous, in addition to magnesium, oxygen, and zinc in the composites due to the added nano-fHA.

Figure 4 presents the XRD plots of pure $\mathrm{Mg}$, fHA, and ball-milled powders. Peaks corresponding to Pure $\mathrm{Mg}$ and fHA were indexed, and the findings support the chemical 
composition analysis (Figure 3) that no contamination present in the powders. Interestingly, the relative intensities of peaks of the composite powders after ball milling were observed as changed. The peak intensity of (002) of the composite powders was significantly increased, and other peak intensities were observed as decreased due to ball milling. (002) peak corresponds to the basal plane in $h c p \mathrm{Mg}$, and therefore, it can be noted that a preferred orientation has occurred within the particles during the plastic deformation. Obtaining a preferred texture in $\mathrm{Mg}$ can alter biodegradation. It was also reported that the basal-dominated texture influences the electrochemical events at the implant-tissue interface and affects the degradation process $[40,41]$. Figure 5 shows the microstructure of the sintered samples. Since the $\mathrm{Mg}$ particles transformed into thin flakes due to the ball milling process, the resulting solid compacts also exhibited the same morphology for the grains in the sintered samples. These gains are similar to the micro-lamellar structure reported in the literature [42]. A large difference in the length to thickness is the main characteristic of microlamellar grains. Due to the lamellar structure at the microscopic level, the developed composites behave differently compared with the constituting phases. The black regions are the interfaces between the lamellar grains, and the bright regions are the grain interiors (Figure 5). Usually, the reinforcing phase is distributed at the interfaces of the grains in the composites developed through ball milling followed by sintering [30, 42]. Therefore, in the present work, the added fHA crystals are believed to be distributed at the interfaces of the grains.
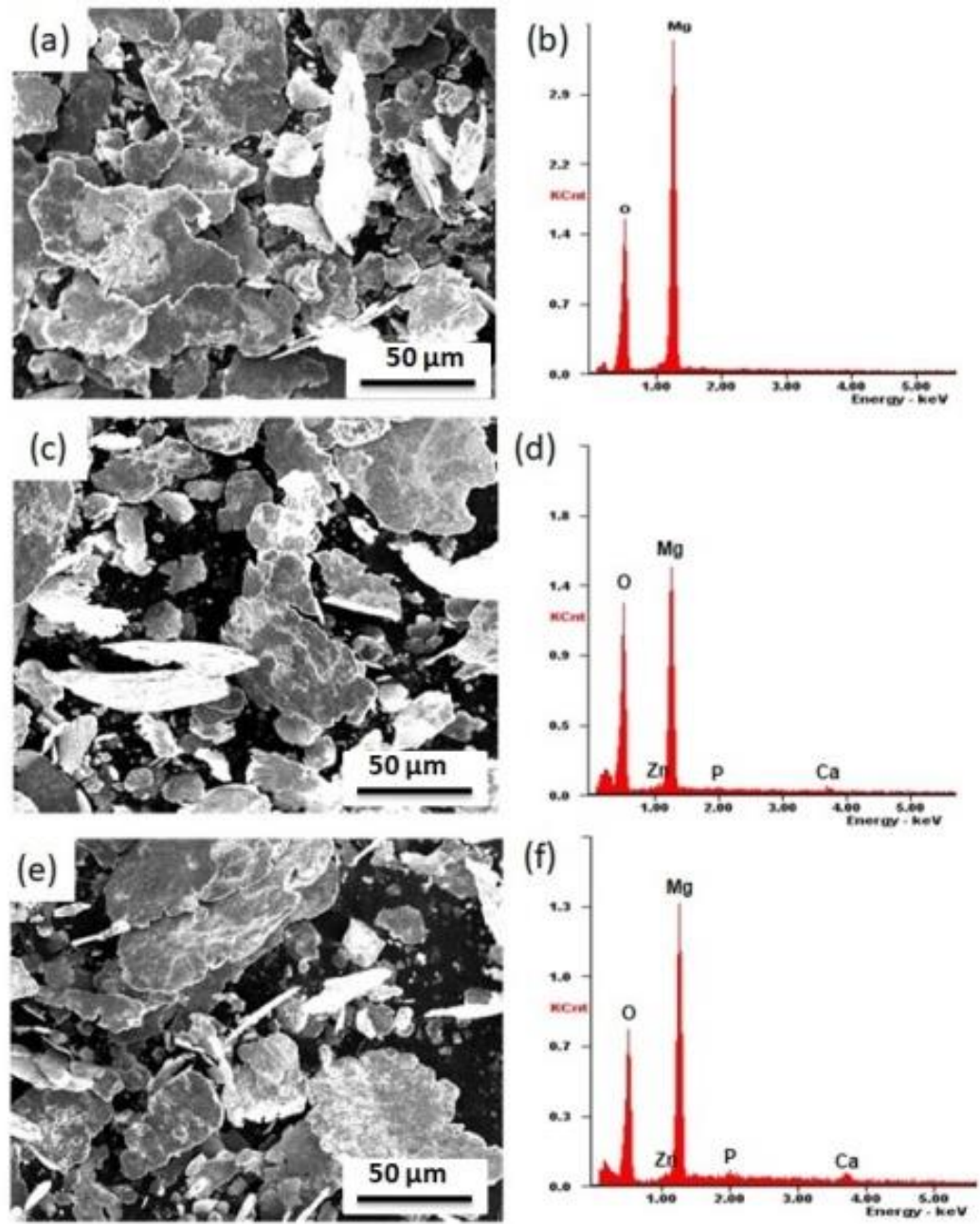

Figure 3. Scanning electron microscope (SEM) images and corresponding EDS analysis of milled powders: (a) and (b) Mg powders, (c) and (d) Mg-Zn-1fHA, (e) and (f) Mg-Zn-2fHA. 

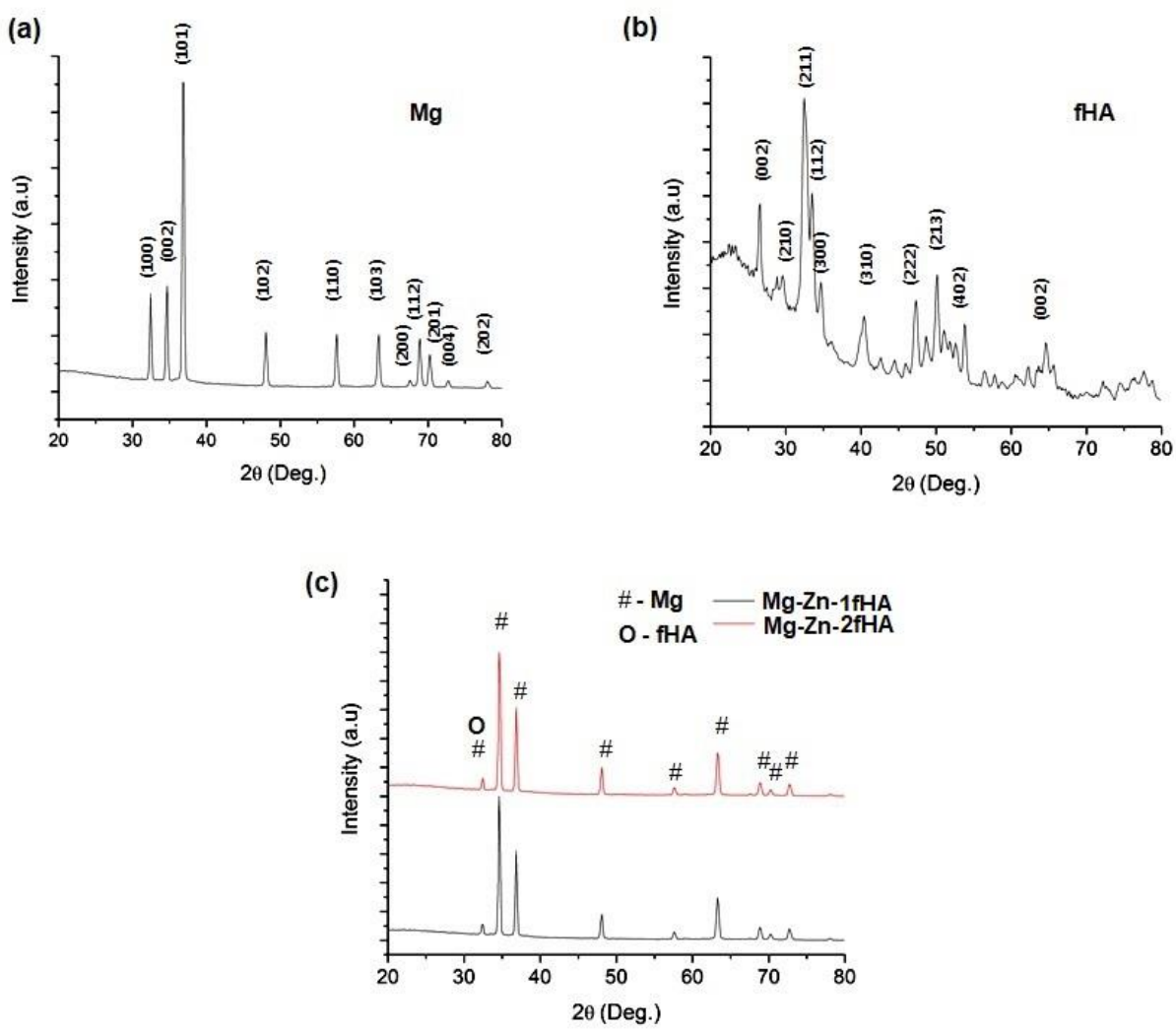

Figure 4. XRD patterns of powders: (a) pure Mg powder, (b) fHA powder, (c) composite powders after ball milling.

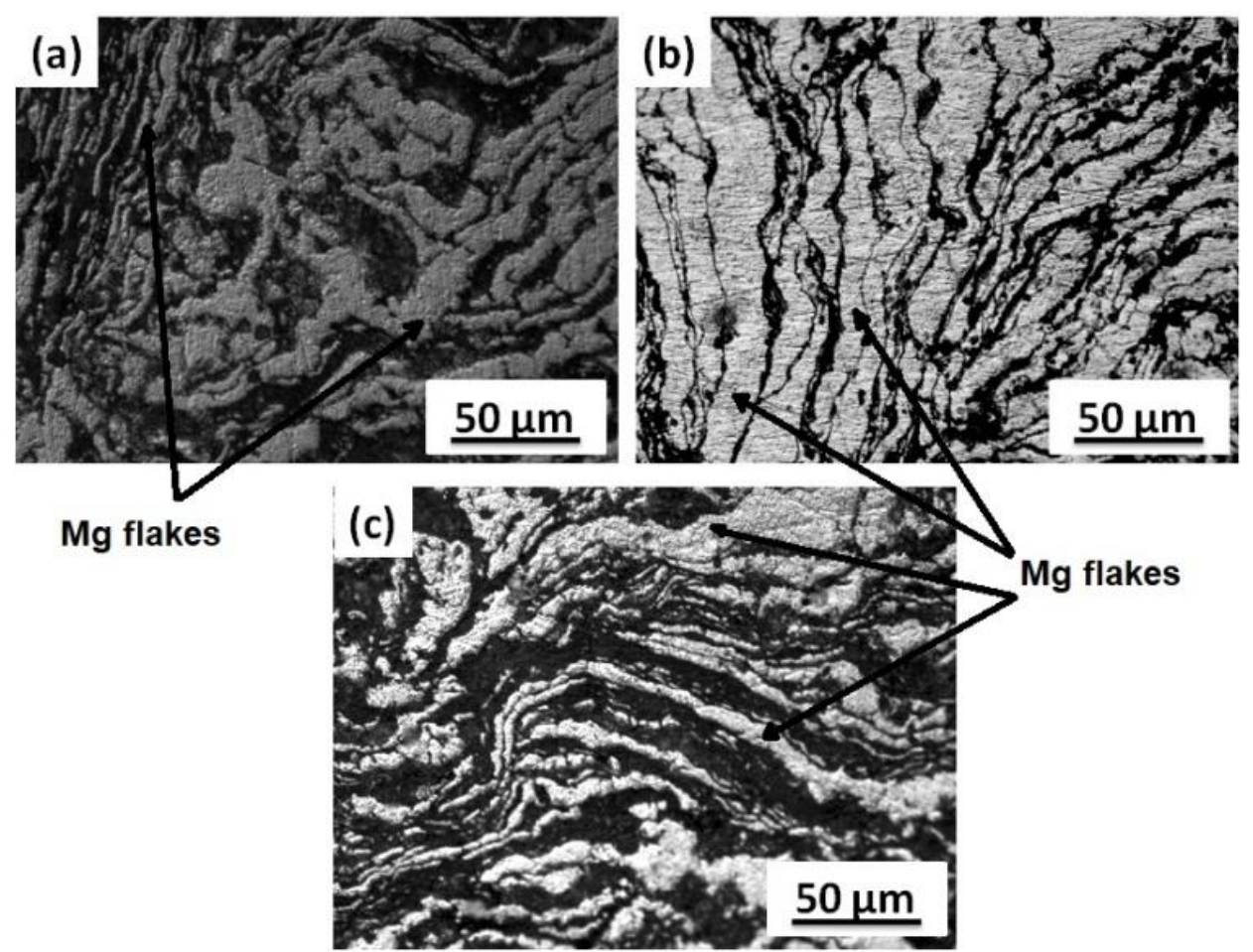

Figure 5. Microstructure of the sintered samples: (a) pure $\mathrm{Mg}$, (b) $\mathrm{Mg}-\mathrm{Zn}-1 \mathrm{fHA}$, and (c) Mg-Zn-2fHA.

Figure 6 presents the morphologies of surface mineral depositions and their corresponding elemental composition obtained from the samples after $72 \mathrm{~h}$ of immersion in SBF. It is evident from the deposited phases and the elemental composition that the presence of fHA has a profound effect on increasing the deposition of phases that contain calcium $(\mathrm{Ca})$ and phosphorous $(\mathrm{P})$ as the main constituting elements. A higher level of deposition of $\mathrm{Ca} / \mathrm{P}$ 
on the composites compared with pure $\mathrm{Mg}$ suggests an increase in the biomineralization, a process by which mineral depositions are influenced at the implant-tissue interface. Microlamellar grain structures with the presence of fHA crystals throughout the composite influenced the biomineralization process. Enhanced mineral deposition helps to lower the degradation process by delaying the dissolution of $\mathrm{Mg}$ from the implant. Furthermore, surfaces with higher mineral depositions are favorable for cell adhesion and growth.
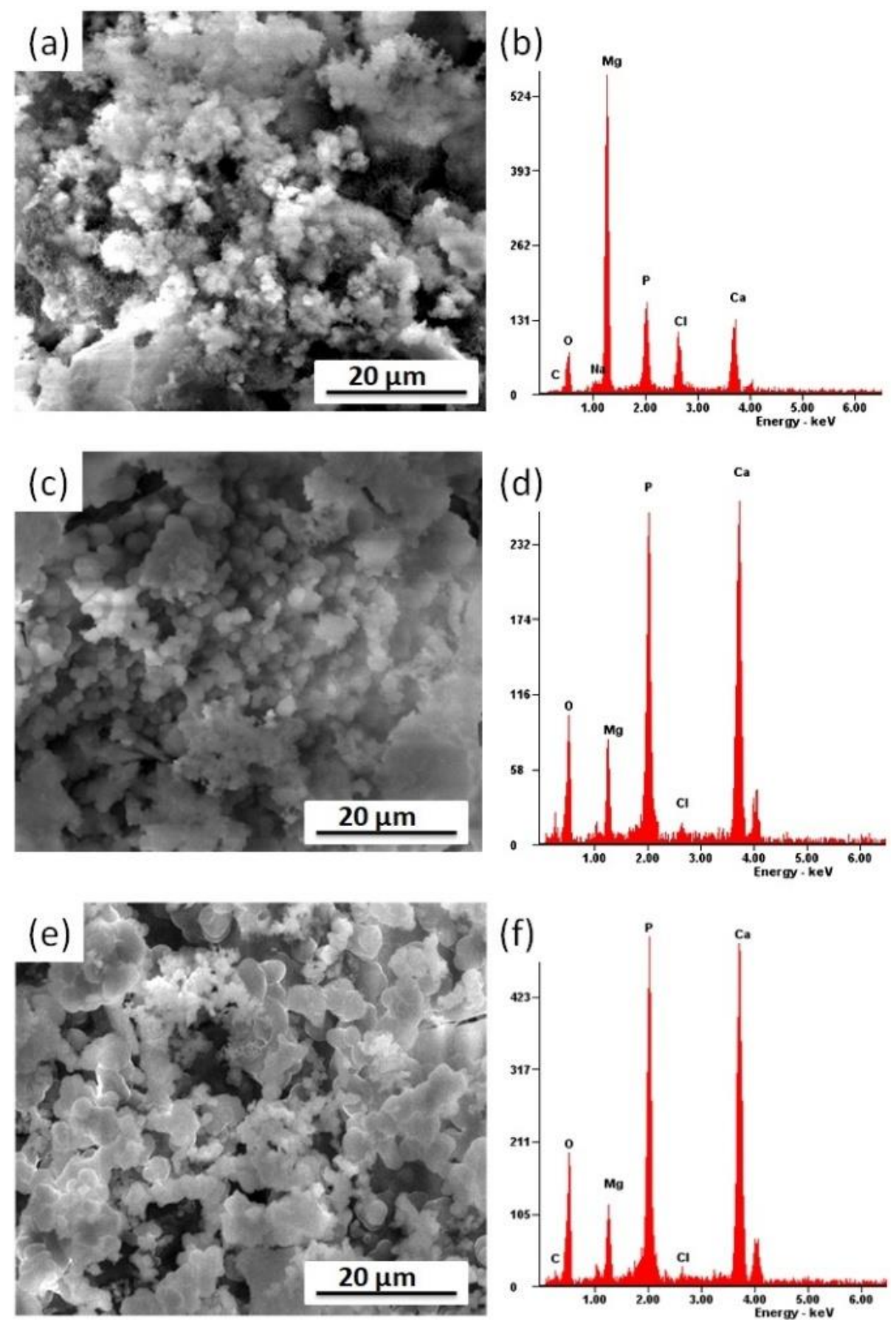

Figure 6. SEM images and chemical composition of the surfaces of the samples after $72 \mathrm{~h}$ in SBF: (a) pure Mg, (b) surface EDS analysis, (c) Mg-Zn-1fHA, (d) surface EDS analysis, (e) Mg-Zn-2fHA, and (f) surface EDS analysis.

The corrosion products are completely removed from the surface of the samples by dissolving them in the chromate solution, and the measured weight loss values of the samples are compared in Figure 7. It is observed that with the increased immersion time from $24 \mathrm{~h}$ to 
$72 \mathrm{~h}$, the degradation rate of the samples was increased. Composites exhibited relatively lower weight loss than pure $\mathrm{Mg}$. Within the composites, the sample with 1\% HA has shown lower degradation compared with the sample having $2 \%$ HA. Both the composites exhibited excellent deposition of mineral phase due to the presence of nano-HA, which accelerated the crystal formation and growth of the $\mathrm{Ca} / \mathrm{P}$ mineral phase from the SBF. However, the presence of more HA increased the degradation rate. This can be explained by considering the galvanic corrosion due to the contact of different phases with varying electrochemical potentials. The presence of more HA (ceramic phase) in Mg (metallic phase) accelerates galvanic corrosion in the composite. The mineral deposition helped to decrease the degradation due to bio-corrosion. When fHA content was increased to $2 \%$ due to the increased galvanic corrosion, the degradation rate was increased compared with $1 \%$ fHA composite. However, enhanced mineral deposition has reduced the overall corrosion of both the composites compared with pure $\mathrm{Mg}$.

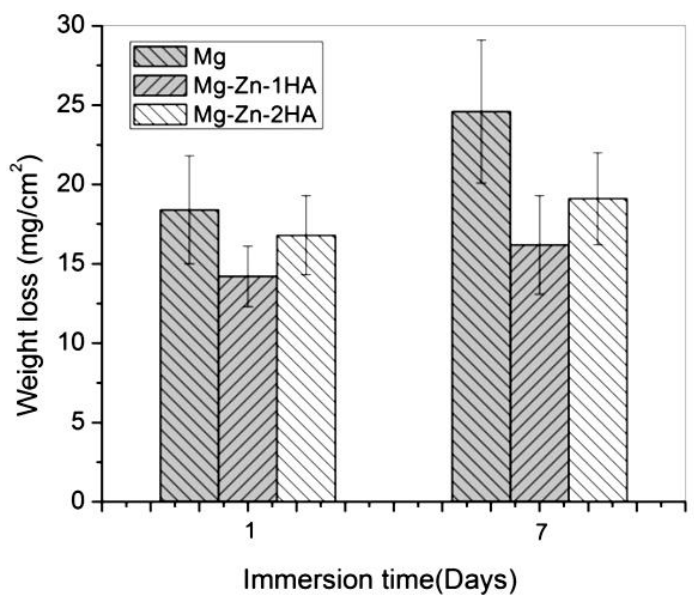

Figure 7. Weight loss measurements of the samples calculated from the immersion studies.

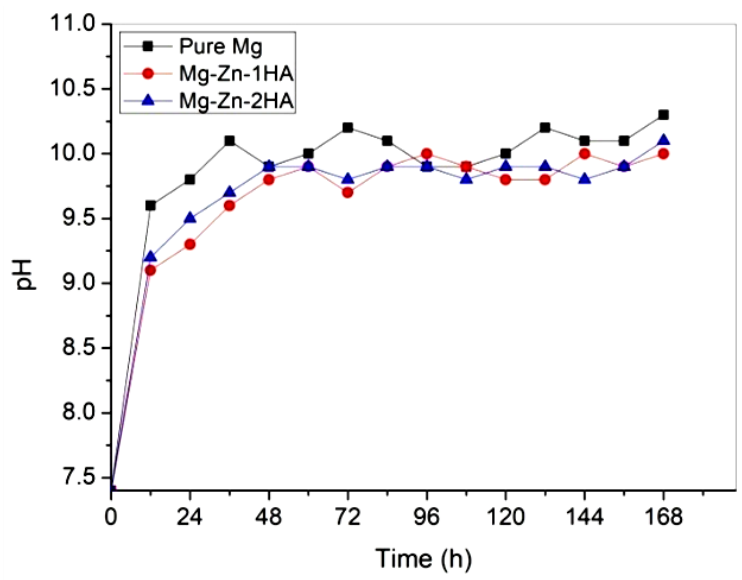

Figure 8. $\mathrm{pH}$ variations in the SBF during the immersion period.

Figure 8 shows the $\mathrm{pH}$ measurements of the SBF solution for the samples recorded for 7 days. The $\mathrm{pH}$ values of the SBF in all the containers were measured and observed as increased due to the nature of aggressive corrosion of Mg during the initial hours of contact with an aqueous solution. During the degradation of $\mathrm{Mg}$ in the presence of a physiological environment, the initial rate of formation of $\mathrm{Mg}(\mathrm{OH})_{2}$ layer as a corrosion by-product on the fresh surface of $\mathrm{Mg}$ is higher. Therefore the change in $\mathrm{pH}$ is rapid in the initial hours of immersion. Once the $\mathrm{Mg}(\mathrm{OH})_{2}$ layer is formed on the surface of $\mathrm{Mg}$, then the corrosion rate is decreased as the $\mathrm{Mg}(\mathrm{OH})_{2}$ layer acts as a barrier. However, due to the presence of $\mathrm{Cl}$ ions, the 
$\mathrm{Mg}(\mathrm{OH})_{2}$ layer is slowly degraded, and $\mathrm{Mg}$ corrosion is further increased. Hence, $\mathrm{pH}$ change is bigger during the initial hours of the immersion. The $\mathrm{pH}$ was found to be stabilized in all the samples with the increased immersion time. Compared with the composites, SBF solution containing pure $\mathrm{Mg}$ was observed with marginally higher $\mathrm{pH}$ values due to more degradation.

Higher mineral depositions help to delay the degradation process by stabilizing the $\mathrm{Mg}(\mathrm{OH})_{2}$ phase produced due to bio-corrosion of $\mathrm{Mg}$ and also delay the transformation of $\left(\mathrm{Mg}(\mathrm{OH})_{2}\right.$ into magnesium chloride [43]. The mineral phases of $\mathrm{Ca} / \mathrm{P}$ also promote better bonding at the implant-tissue interface [30]. Therefore, a higher rate of biomineralization is always preferred in developing Mg-based implants to achieve lower degradation and a higher rate of healing $[44,45]$. In the present work, lamellar microstructure and incorporated nanofHA crystals are the two important factors that played an important role in increasing the biomineralization by which the degradation was decreased. Hence, from the results, it can be summarized that ball milling results in the micro-lamellar structure which is also seen in the sintered Mg-Zn-fHA composites. The added fHA crystals enhanced biomineralization which is favorable for degradable implant applications. The present results encourage future studies with other potential $\mathrm{Mg}$ alloys (with biocompatible alloying elements) as matrix material.

\section{Conclusions}

Composites of Mg-Zn-fish bone-derived hydroxyapatite (fHA) with micro-lamellar morphology were produced with $1 \%$ and $2 \%$ fHA content by ball milling and sintering. The XRD studies showed no indication of the formation of any new phases after milling. The altered peak intensities indicate basal texture in the milled powders. The ball-milled powders were observed with a flake-like structure, and the same has been retained after sintering and appeared as a micro-lamellar structure. Immersion studies in simulated body fluids indicated better mineral deposition of $\mathrm{Ca} / \mathrm{P}$ phase on the composites than pure $\mathrm{Mg}$. $\mathrm{pH}$ measurements also indicated lower degradation for the composites. Composite with $1 \%$ HA was observed with lower weight loss than composite with $2 \%$ HA. Hence for the results, it can be concluded that $\mathrm{Mg}-\mathrm{Zn}-1 \% \mathrm{HA}$ can be a viable composition with a micro-lamellar structure to manufacture $\mathrm{Mg}$ based implants for degradable biomedical implants.

\section{Funding}

This research received no external funding.

\section{Acknowledgments}

This research has no acknowledgment.

\section{Conflicts of Interest}

The authors declare no conflict of interest.

\section{References}

1. Nikhilesh, C.; Krishan K.C. Metal Matrix Composites. $2^{\text {nd }}$ ed., Springer, New York, 2013; pp. 37-54, https://doi.org/10.1007/978-1-4614-9548-2.

2. Yi, L.J.; Li, J.F.; Ma, M.G.; Zhu, Y.J. Nanostructured Calcium-Based Biomaterials and Their Application in

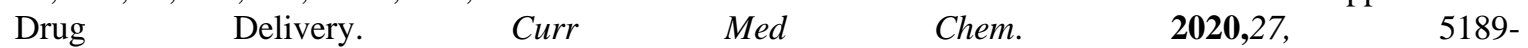
5212,https://doi.org/10.2174/0929867326666190222193357. 
3. Antoniac, I.; Adam, R.; Bita, A.; Miculescu, M.; Trante, O.; Petrescu, I.M.; Pogarasteanu, M. Comparative Assessment of In Vitro and In Vivo Biodegradation of Mg-1Ca Magnesium Alloys for Orthopedic Applications. Materials 2021, 14, https://dx.doi.org/10.3390/ma14010084.

4. Li, W.; Shen, Y.; Shen, J.; Shen, D.; Liu, X.; Zheng, Y.; Yeung, K.W.K.; Guan, S.; Kulyasova, O.B.; Valiev, R.Z. In vitro and in vivo studies on pure $\mathrm{Mg}, \mathrm{Mg}-1 \mathrm{Ca}$ and $\mathrm{Mg}-2 \mathrm{Sr}$ alloys processed by equal channel angular pressing. Nano Mater. Sci.2020, 2, 96-108, https://doi.org/10.1016/j.nanoms.2020.03.004.

5. Hang, Z.; Bing, Liang.; Haitao, J.; Zhongliang, D.; Kexiao Y. Magnesium-Based Biomaterials as Emerging Agents for Bone Repair and Regeneration: From Mechanism to Application.J. Magnes. Alloys. 2021,9, 779804, https://doi.org/10.1016/j.jma.2021.03.004.

6. Shukufe, A.; Masoud, M. Biodegradable Magnesium-Based Biomaterials: An Overview Of Challenges And Opportunities.Medcomm2021,2, 123-144,https://doi.org/10.1002/mco2.59.

7. Herber, V.; Okutan, B.; Antonoglou, G.; Sommer, N.G.; Payer, M. Bioresorbable Magnesium-Based Alloys as Novel Biomaterials in Oral Bone Regeneration: General Review and Clinical Perspectives. J. Clin. Med. 2021, 10, https://doi.org/10.3390/jcm10091842.

8. Witte, F.; Hort, N.; Vogt, C.; Cohen, S.; Kainer, K.U.; Willumeit, R.; Feyerabend, F. Degradable Biomaterials Based on Magnesium Corrosion. Curr Opin Solid St Mater Sci.2008, 12, 6372,https://doi.org/10.1016/j.cossms.2009.04.001.

9. Rahman, M.; Dutta Naba, K.; Namita, R.C. Magnesium Alloys with Tunable Interfaces as Bone Implant Materials.Front. Bioeng. Biotechnol. 2020, 8, https://doi.org/10.3389/fbioe.2020.00564.

10. Shebeer, A.R.; Muhammad Rabeeh, V.P.; Joseph, M.A.; Hanas, T. Does Acid Pickling of Mg-Ca Alloy Enhance Biomineralization? J. Magnes. Alloys 2021, 9, 1028-1038, https://doi.org/10.1016/j.jma.2020.12.002.

11. Kirkland, N. T.; Birbilis, N. Magnesium biomaterials design, testing, and best practice. Springer, New York, USA, 2014;pp. 1-131, https://doi.org/10.1007/978-3-319-02123-2.

12. Zeng, R.; Dietzel, W.; Witte, F.; Hort, N.; Blawert, C. Progress and Challenge for Magnesium Alloys as Biomaterials. Adv Eng Mater. 2008, 10, B3-B14,https://doi.org/10.1002/adem.200800035.

13. Sourav, D.; Sanjay, G.; Roy, M. Recent Developments in Magnesium Metal-Matrix Composites for Biomedical Applications: A Review.ACS Biomater. Sci. Eng.2020,6, 4748-4773, https://doi.org/10.1021/acsbiomaterials.0c00678.

14. Saberi, A.; Bakhsheshi-Rad, H.R.; Karamian, E.; Kasiri-Asgarani, M.; Ghomi, H.; Omidi, M.; Abazari, S.; Ismail, A.F.; Sharif, S.; Berto, F. Synthesis and Characterization of Hot Extruded Magnesium-Zinc NanoComposites Containing Low Content of Graphene Oxide for Implant Applications. Phys. Mesomech.2021,24, 486-502,https://doi.org/10.1134/S1029959921040135.

15. Sandeep Moudgalya, K.V.; Suresh Hebbar, H. Magnesium Based Biocomposites for Biomedical Applications - A Review.AIP Conference Proceedings2020, 2247, https://doi.org/10.1063/5.0003896.

16. de Castro, M.M; Lopes D.R.; Dias, L.V. Mg-Based Composites for Biomedical Application. Intech Open, 2021; https://doi.org/10.5772/intechopen.95079.

17. Lin, K.; Chang, J. Structure and Properties of Hydroxyapatite for Biomedical Applications, Editor(s): Michael Mucalo. In: Hydroxyapatite (Hap) for Biomedical Applications. Woodhead Publishing Series in Biomaterials, Woodhead Publishing, 2015;pp. 3-19, https://doi.org/10.1016/B978-1-78242-033-0.00001-8.

18. Amaechi, B.T.; AbdulAzees, P.A.; Alshareif, D.O.; Shehata, M.A.; Lima, P.P.d.C.S.; Abdollahi, A.; Kalkhorani, P.S.; Evans, V. Comparative Efficacy of a Hydroxyapatite and a Fluoride Toothpaste for Prevention and Remineralization of Dental Caries in Children.BDJ Open2019, 5,https://doi.org/10.1038/s41405-019-0026-8.

19. Vivekanand, S.K.; Sudheer, K.; Krishna Prasad, L. Hydroxyapatite-Past, Present, And Future In Bone Regeneration. Bone and Tissue Regeneration Insights2016,7, 9-19,https://doi.org/10.4137/BTRI.S36138.

20. Cestari, F.; Agostinacchio, F.; Galotta, A.; Chemello, G.; Motta, A.; Sglavo, M.V. Nano-Hydroxyapatite Derived from Biogenic and Bioinspired Calcium Carbonates: Synthesis and In Vitro Bioactivity. Nanomaterials2021, 11, https://doi.org/10.3390/nano11020264.

21. Sawada, M.; Sridhar, K.; Kanda, Y.; Yamanka, S. Pure Hydroxyapatite Synthesis Originating from Amorphous Calcium Carbonate. Sci Rep2021, 11, https://doi.org/10.1038/s41598-021-91064-y.

22. Masakuni, O.; Suguru, S. Microstructural Development of Natural Hydroxyapatite Originated from FishBone Waste through Heat Treatment.J. Am. Ceram. Soc. 2002, 85, 13151317,https://doi.org/10.1111/j.1151-2916.2002.tb00268.x.

23. Boutinguiza, M.; Pou, J.; Comesaña, R.; Lusquiños, F.; de Carlos, A.; León, B. Biological Hydroxyapatite Obtained from Fish Bones.Mater. Sci. Eng. C2012, 32, 478-486,https://doi.org/10.1016/j.msec.2011.11.021.

24. Huang, Y.C.; Hsiao, P.C.; Chai, H.J. Hydroxyapatite Extracted From Fish Scale: Effects on MG63 Osteoblast-Like Cells. Ceram. Int. 2011, 37, 1825-1831,https://doi.org/10.1016/j.ceramint.2011.01.018.

25. Santos, M.H.; de Oliveira, M.; de Freitas Souza, P.; Mansur, H.S.; Vasconcelos, W.L. Synthesis Control and Characterization of Hydroxyapatite Prepared by Wet Precipitation Process.Mater. Res. 2004, 7, 625630,https://doi.org/10.1590/S1516-14392004000400017.

26. Kojima, Y.; Kitazawa, K.; Nishimiya, N. Synthesis of Nano-Sized Hydroxyapatite By Ultrasound Irradiation.J. Phys.: Conf. Ser.2012, 339,https://doi.org/10.1088/1742-6596/339/1/012001. 
27. Suchanek, W.L.; Riman, R.E. Hydrothermal Synthesis of Advanced Ceramic Powders.Adv. Sci. Technol. 2006, 45, 184-193,https://doi.org/10.4028/www.scientific.net/AST.45.184.

28. Cho, J.S.; Kang, Y.C. Nano-Sized Hydroxyapatite Powders Prepared by Flame Spray Pyrolysis.J. Alloy. Compd. 2008, 464, 282-287,https://doi.org/10.1016/j.jallcom.2007.09.092.

29. Ratna Sunil, B.; Jagannatham, M. Producing Hydroxyapatite from Fish Bones by Heat Treatment.Mater Let 2016,185, 411-414, http://dx.doi.org/10.1016/j.matlet.2016.09.039.

30. Suryanarayana, C. Mechanical Alloying and Milling.Prog. Mater. Sci. 2001,46, 1-184, https://doi.org/10.1016/S0079-6425(99)00010-9.

31. Khanra, A.K.; Jung, H.C.; Yu, S.H.; Hong, K.S.; Shin, K.S. Microstructure and Mechanical Properties of Mg-HAP Composites. Bull. Mater. Sci. 2010,33, 43-47,https://doi.org/10.1007/S12034-010-0006-Z.

32. Gu, X.; Zhou, W.; Zheng, Y.; Dong, L.; Xi, Y.; Chai, D. Microstructure, Mechanical Property, Bio-Corrosion and Cytotoxicity Evaluations of $\mathrm{Mg} / \mathrm{HA}$ Composites. Mater. Sci. Eng. C. 2010, 30, 827832,https://doi.org/10.1016/j.msec.2010.03.016.

33. Ye, X.; Chen, M.; Yang, M.; Wei, J.; Liu, D. In Vitro Corrosion Resistance and Cytocompatibility of NanoHydroxyapatite Reinforced $\mathrm{Mg}-\mathrm{Zn}-\mathrm{Zr}$ Composites. J. Mater. Sci.: Mater. Med. 2010, 21, 13211328,https://doi.org/10.1007/s10856-009-3954-3.

34. Khalil, K.A.; Almajid, A. Effect of High-Frequency Induction Heat Sintering Conditions on the Microstructure and Mechanical Properties of Nanostructured Magnesium/Hydroxyapatite Nanocomposites. Mater. Des. 2012, 36, 58-68,https://doi.org/10.1016/j.matdes.2011.11.008.

35. Ratna Sunil, B.; Sampath Kumar, T.S.; Uday Chakkingal; Nandakumar, V.; Mukesh D. Nano-Hydroxyapatite Reinforced AZ31 Magnesium Alloy by Friction Stir Processing: A Solid State Processing for Biodegradable Metal Matrix Composites.J. Mater. Sci. Mater. Med.2014,25, 975-988,https://doi.org/10.1007/s10856-0135127-7.

36. Avedesian, M.; Baker, H. ASM Specialty Handbook:Magnesium and Magnesium Alloys. ASM International, USA, 1999.

37. Kevorkov, D.; Pekguleryuz, M. Experimental Study of The Ce-Mg-Zn Phase Diagram at $350^{\circ} \mathrm{C}$ via Diffusion Couple Techniques.J. Alloys Compd.2009, 478, 427436,https://doi.org/10.1016/j.jallcom.2008.11.119.

38. Syam, P.U.; Kondaiah, V.V.; Akhil, K.; Kumar, V.V.; Nagamani, B.; Jhansi, K.; Dumpala, R.; Venkateswarlu, B.; Ratna, S.B. Effect of Heat Treatment on Microstructure, Microhardness and Corrosion Resistance of ZE41 Mg Alloy.Koroze A Ochrana Materiálu. 2019, 63, 79-85,https://doi.org/10.2478/kom2019-0010.

39. Kokubo, T.; Takadama, H. How Useful is SBF in Predicting in vivo Bone Bioactivity? Biomaterials 2006, 27, 2907-15,https://doi.org/10.1016/j.biomaterials.2006.01.017.

40. Ratna Sunil, B.; Sampath Kumar, T.S.; Uday Chakkingal; Nandakumar, V.; Mukesh, D. Friction Stir Processing of Magnesium - Nanohydroxyapatite Composites with Controlled in vitro Degradation Behaviour.Mater. Sci. Eng. C2014,39, 315-324,https://doi.org/10.1016/j.msec.2014.03.004.

41. Saikrishna, N.; Pradeep Kumar Reddy, G.; Balakrishnan, M.; Ravikumar D.; Jagannatham, M.; Ratna Sunil, B. An Investigation on the Hardness and Corrosion Behaviour of MWCNT/Mg Composites and Grain Refined Mg.J. Magnes. Alloys2018, 6,83-89, https://doi.org/10.1016/j.jma.2017.12.003.

42. Ratna Sunil, B.; Ganapathy, C.; Sampath Kumar, T.S.; Uday, C. Processing and Evaluating Mechanical Behaviour of Lamellar Structured Degradable Magnesium-Hydroxyapatite Implants.J. Mech. Behav. Biomed. Mater. 2014,40, 178-189,https://doi.org/10.1016/j.jmbbm.2014.08.016.

43. Witte, F.; Fischer, J.; Nellesen, J.; Crostack, H.-A.; Kaese, V.; Pisch, A.; Beckmann, F.; Windhagen, H. In Vitro and In Vivo Corrosion Measurements of Magnesium Alloys. Biomaterials.2006, 27, 10138,https://doi.org/10.1016/j.biomaterials.2005.07.037.

44. Ho, Y.-H.; Man, K.; Joshi, S.S.; Pantawane, M.V.; Wu, T.-C.; Yang, Y.; Dahotre, N.B. In-Vitro Biomineralization and Biocompatibility of Friction Stir Additively Manufactured AZ31B Magnesium Alloy$\begin{array}{llll}\text { Hydroxyapatite } & \text { Composites.Bioact. } & \text { Mater. } & \text { 2020,5, }\end{array}$ https://doi.org/10.1016/j.bioactmat.2020.06.009.

45. Bakhsheshi-Rad, H.R.; Hamzah, E.; Ying, W.S.; Razzaghi, M.; Sharif, S.; Ismail, A.F.; Berto, F. Improved Bacteriostatic and Anticorrosion Effects of Polycaprolactone/Chitosan Coated Magnesium via Incorporation of Zinc Oxide. Materials 2021, 14, https://doi.org/10.3390/ma14081930. 